\title{
Association of Mean Platelet Volume With Androgens and Insulin Resistance in Nonobese Patients With Polycystic Ovary Syndrome
}

\author{
Bercem Aycicek Dogan ${ }^{1, *}$; Ayse Arduc ${ }^{2}$; Mazhar Muslum Tuna ${ }^{1}$; Ersen Karakılıc ${ }^{1}$; Iffet \\ Dagdelen ${ }^{1}$; Yasemin Tutuncu ${ }^{1}$; Dilek Berker ${ }^{1}$; Serdar Guler ${ }^{1}$ \\ ${ }_{1}^{1}$ Ankara Numune Training and Research Hospital, Endocrinology and Metabolism Disease, Ankara, Turkey \\ ${ }^{2}$ National Institute of Diabetes and Digestive and Kidney Diseases, Diabetes-Endocrine and Obesity Branch, National Institutes of Health, Bethesda, Maryland, USA \\ ${ }^{*}$ Corresponding author: Bercem Aycicek Dogan, Ankara Numune Training and Research Hospital, Endocrinology and Metabolism Disease, Ankara, Turkey. Tel: +90-3125084734, Fax: \\ +90-3123114340, E-mail: bercemay@gmail.com
}

Received: March 02, 2014; Revised: April 13, 2014; Accepted: May 17, 2014

\begin{abstract}
Background: Mean platelet volume (MPV) is generally accepted as a new marker of cardiovascular disease risk in several studies. Objectives: This study aimed to determine the association of MPV with androgen hormones and insulin resistance (IR) in nonobese patients with polycystic ovary syndrome (PCOS).

Patientsand Methods:A total of 136 patients with newly diagnosed reproductive-age PCOS(regarding the criteria of new PCOS phenotypes, based on the Rotterdam criteria) who were nonobese with the mean age of 25 years (25.39 \pm 5.51 )and mean body mass index (BMI) of $21 \mathrm{~kg} /$ $\mathrm{m}^{2}(22.07 \pm 2.13)$ were included. In addition, 59 healthy subjects with mean age of 26 years $(22.07 \pm 2.13)$ and mean BMI of $22 \mathrm{~kg} / \mathrm{m}^{2}(21.52 \pm$ 3.84) were recruited as control. Total blood count (including MPV), total testosterone, free testosterone, dehydroepiandrosterone-sulfate (DHEAS), and androstenedione levels were recorded. IR was calculated from blood chemistry measurements of fasting insulin and glucose according to updated homeostasis model assessment.

Results: No differences were observed in mean MPV values between patients and control group (9.02 fL (8.5-10.1) and 8.9 fL (7.7-9.1), respectively; $\mathrm{P}=0.777)$. MPV values were similar among nonobese patients with and without IR and control subjects $(\mathrm{P}>0.05)$. We detected significantly lower values of MPV in patients with hyperandrogenemia in comparison to patients with normal androgen levels ( 8.7 and 9.5 fL, $\mathrm{P}=0.012)$. There was a negative correlation between total testosterone, DHEAS, and MPV $(\mathrm{P}=0.016, \mathrm{r}=-0.229$; and $\mathrm{P}=0.006, \mathrm{r}=-0.261$, respectively). Multiple logistic regression analyses confirmed the independence of these associations.

Conclusions: Our study revealed that nonobese women with and without PCOS have similar MPV values. While IR does not have any effect on MPV, elevated androgen levels are associated with a low MPV in nonobese patients with PCOS.
\end{abstract}

Keywords:Androgen Hormones; Mean Platelet Volume; Polycystic Ovary Syndrome

\section{Background}

Polycystic ovary syndrome (PCOS) is a common endocrine disorder in women at reproductive age $(1,2)$. PCOS is diagnosed with oligomenorrhea and/or anovulation as well as clinical and/or biochemical hyperandrogenemia with/without ultrasonographic evidence of polycystic ovaries. The diagnosis is made after exclusion of other disorders including thyroid dysfunction, hyperprolactinemia, nonclassical adrenal hyperplasia, Cushing syndrome, and androgen producing tumors (3). According to Androgen Excess Society (AES), PCOS phenotypes including phenotype of hyperandrogenism and oligomenorrhea had a higher prevalence of metabolic syndrome when matched with the control subjects $(4,5)$; moreover, recent data support an increased incidence of cardiovascular events in women with PCOS, which are related to androgens level (6-8). PCOS is also associated with an increased risk of insulin resistance(IR), type 2 diabetes mellitus, dyslipidemia, and atherosclerosis (9-13). IR is also a risk factor for metabolic abnormalities and increases the risk of cardiovascular events. High mean platelet volume (MPV) might contribute to the endothelial injury by platelet activation and higher plasma concentrations of thromboxane A2 (14). Several reports have demonstrated that there is an association between MPV and cardiovascular risk factors (15) such as obesity (16), diabetes mellitus (17), hypertension (18), acute coronary syndrome (19), and stroke (20). According to AES, IR and hyperandrogenemia are risk factors for cardiovascular diseases in patients with PCOS $(4,5)$. Regarding the current evidences, it is reasonable to investigate the association of MPV with androgens as well as IR in patients with PCOS.

\section{Objectives}

To our knowledge, just one study investigated the association of MPV with androgen levels in patients with PCOS (20); however, the mentioned study included overweight and obese patients. Therefore, our study was designed to determine whether there was any association between androgens/IR and MPV in nonobese patients with PCOS.

Copyright (C) 2014, Research Institute For Endocrine Sciences and Iran Endocrine Society; Published by Kowsar. This is an open-access article distributed under the terms of the Creative Commons Attribution-NonCommercial 4.0 International License (http://creativecommons.org/licenses/by-nc/4.0/) which permits copy and redistribute the material just in noncommercial usages, provided the original work is properly cited. 


\section{Patients and Methods}

\subsection{Study and Control Subjects}

A total of 136 patients with newly diagnosed reproductive-age PCOS (regarding to criteria of new PCOS phenotypes, based on the Rotterdam criteria) (3) who were nonobese (body mass index [BMI], 20-25 kg/m²) were included. For control group, 59 healthy subjects (BMI, 20-25 $\mathrm{kg} / \mathrm{m}^{2}$ ) were recruited.

All patients completed a standard questionnaire regarding their detailed history of menstrual cycles, acne, hirsutism, and medications. Oligomenorrhea was defined as menstrual cycles occurring at intervals $>35$ days, with only four to nine periods in a year. BMI $\left(\mathrm{kg} / \mathrm{m}^{2}\right)$ was calculated by dividing weight in kilograms by the square of height in meters. The presence of terminal hair growth was scored using Ferriman-Gallwey Method (21); hirsutism was defined as a score $>8$ (22). The presence or absence of acanthosis nigricans and acne were noted. All women had normal thyroid, renal, and hepatic function test results.

Individuals with hyperprolactinemia, congenital adrenal hyperplasia, Cushing's syndrome, and those who had taken hormonal treatment for at least three months prior to their evaluation were excluded. Furthermore, patients with hypertension and a history of angina or myocardial infarction, obesity, diabetes mellitus, diagnosed coagulation abnormalities or abnormal results of hematological parameters, any systemic disease, vascular or thyroid disorders, infection or inflammatory diseases, and malignancy were excluded. In addition, subjects who had taken any medication affecting MPV value were excluded. The control group consisted of healthy women with regular menstrual cycles, normal BMI, and no medication during preceding three months.

\subsection{Biochemical Analysis}

Venous blood samples for assessing FSH and LH (mIU/ $\mathrm{mL})$, estradiol $(\mathrm{pg} / \mathrm{mL})$, prolactin $(\mathrm{ng} / \mathrm{mL})$, total testosterone $(\mathrm{ng} / \mathrm{mL})$, androstenedione $(\mathrm{ng} / \mathrm{mL})$, and dehydroepiandrosterone-sulfate (DHEAS) $(\mu \mathrm{g} / \mathrm{dL})$ were obtained from all participants in the morning between 08:00 A.M. and 09:00 A.M. after an overnight fast. Serum FSH, LH, total testosterone, estradiol, progesterone, and DHEAS levels were measured by the chemiluminescent microparticle immunoassay (paramagnetic particle, chemiluminescent immunoassay) using a Unicel DxI 800 System immuneanalyzer (Beckman Coulter Ireland Inc., Ireland) with original reagents. Radioimmunoassay (RIA) with commercial kits was employed to assess serum free testosterone (BioSource, Nivelles, Belgium) and androstenedione levels (Radim, Roma, Italy). Complete blood count including MPV was assessed using Roche SYSMEX device.

\subsection{Measuring Insulin Resistance}

Insulin $(\mu \mathrm{IU} / \mathrm{mL})$ was analyzed by electrochemiluminescence immunoassay (ECLIA) and via Roche Hitachı
Cobalt 600 device. Fasting blood glucose $(\mathrm{mg} / \mathrm{dL})$ levels were measured by the Roche Hitachi T800 device. IR was calculated by the IR index as determined by homeostasis model assessment (HOMA-IR) with the following formula: fasting blood glucose $(\mathrm{mg} / \mathrm{dL}) \times$ fasting insulin $(\mu \mathrm{IU} /$ $\mathrm{mL}) / 405$; values $>2.7$ were considered as IR.

\subsection{Transvaginal Ultrasonography}

A radiologist performed transvaginal ultrasonography examination of the ovaries in all participants. Ovarian volume was calculated by the following formula: $V=(\pi / 6)$ $\times$ length $(\mathrm{mm}) \times$ width $(\mathrm{mm}) \times$ thickness $(\mathrm{mm})$. The presence of polycystic ovaries was diagnosed by the presence of 12 or more follicles in each ovary with $2-\mathrm{mm}$ to $9-\mathrm{mm}$ diameter and/or increased ovarian volume $\left(>10 \mathrm{~cm}^{3}\right)$.

\subsection{Statistical Analysis}

Data analysis was performed using PASW 18 (IBM, Armonk, NY, USA). Quantitative data were expressed as mean \pm standard deviation or median (range). Frequency (percentage) was used for categorical variables. When comparing the continuous variables Student's t test was used for the normally distributed subset and Mann-Whitney $U$ test was used for the otherwise distributed subset. Pearson Chi square or Fisher's exact tests were used for categorical variables. Linear regression analysis was performed for statistically significant data in correlation test. P value $<0.05$ was considered as statistically significant.

\subsection{Ethic Committee}

The approval of the study protocol was obtained from Institutional Review Board and each participant signed an informed consent regarding the principles in the Declaration of Helsinki.

\section{Results}

There were no significant differences between patients and controls with respect to age $(\mathrm{P}=0.07)$ and $\mathrm{BMI}(\mathrm{P}=$ 0.312) (Table 1).

Table 1. Comparison of Age and Body Mass Index of the Patients With Polycystic Ovary Syndrome and Control Groups ${ }^{\mathrm{a}}$

\begin{tabular}{lccc}
\hline Groups & Number of Patients & Mean \pm SD & Pvalue \\
\hline Age & 59 & $26.91 \pm 4.92$ & 0.070 \\
$\quad$ Controls & 136 & $25.39 \pm 5.51$ & \\
$\quad \begin{array}{l}\text { Patients With } \\
\text { PCOS }\end{array}$ & & 0.312 \\
BMI & 57 & $22.07 \pm 2.13$ & \\
$\quad$ Controls & 106 & $21.52 \pm 3.84$ \\
$\begin{array}{l}\text { Patients With } \\
\text { PCOS }\end{array}$ & & \\
\hline $\begin{array}{l}\text { a Abbreviations: BMI, body mass index; and PCOS, polycystic ovary } \\
\text { syndrome. }\end{array}$
\end{tabular}


Aycicek Dogan B et al.

Table 2. Hormonal Parameters of the Patients With Polycystic Ovary Syndrome and Control Groups ${ }^{\mathrm{a}}$

\begin{tabular}{|c|c|c|c|}
\hline & $\begin{array}{l}\text { Control } \\
\text { Patients }\end{array}$ & $\begin{array}{c}\text { Patients With } \\
\text { PCOS }\end{array}$ & PValue \\
\hline Estradiol & & & 0.016 \\
\hline $\mathrm{N}$ & 57 & 130 & \\
\hline Mean & 60.77 & 78.84 & \\
\hline Median & 52.00 & 55.00 & \\
\hline $\mathrm{SD}$ & 37.90 & 62.24 & \\
\hline Minimum & 22.56 & 17.00 & \\
\hline Maximum & 225.00 & 355.00 & \\
\hline Free testosterone & & & $<0.001$ \\
\hline $\mathrm{N}$ & 55 & 125 & \\
\hline Mean & 1.38 & 2.50 & \\
\hline Median & 1.40 & 2.41 & \\
\hline SD & 0.65 & 1.03 & \\
\hline Minimum & 0.30 & 0.25 & \\
\hline Maximum & 3.00 & 4.71 & \\
\hline Total testosterone & & & $<0.001$ \\
\hline $\mathrm{N}$ & 59 & 135 & \\
\hline Mean & 0.38 & 0.68 & \\
\hline Median & 0.34 & 0.66 & \\
\hline SD & 0.20 & 0.32 & \\
\hline Minimum & 0.12 & 0.13 & \\
\hline Maximum & 0.94 & 1.65 & \\
\hline Androstenedione & & & $<0.001$ \\
\hline $\mathrm{N}$ & 45 & 102 & \\
\hline Mean & 1.00 & 3.07 & \\
\hline Median & 0.84 & 2.57 & \\
\hline SD & 0.60 & 2.19 & \\
\hline Minimum & 0.20 & 0.23 & \\
\hline Maximum & 2.50 & 10.00 & \\
\hline \multicolumn{4}{|l|}{ DHEAS } \\
\hline $\mathrm{N}$ & 58 & 134 & $<0.001$ \\
\hline Mean & 171.87 & 317.50 & \\
\hline Median & 162.36 & 316.21 & \\
\hline SD & 76.93 & 155.09 & \\
\hline Minimum & 53.00 & 50.30 & \\
\hline Maximum & 351.00 & 726.00 & \\
\hline \multicolumn{4}{|l|}{ FSH } \\
\hline $\mathrm{N}$ & 58 & 129 & 0.103 \\
\hline Mean & 6.10 & 5.52 & \\
\hline Median & 6.20 & 5.64 & \\
\hline SD & 2.70 & 2.00 & \\
\hline Minimum & 1.21 & 1.46 & \\
\hline Maximum & 19.90 & 12.56 & \\
\hline LH & & & 0.006 \\
\hline $\mathrm{N}$ & 58 & 128 & \\
\hline Mean & 7.10 & 9.41 & \\
\hline Median & 6.28 & 7.28 & \\
\hline SD & 4.06 & 7.17 & \\
\hline Minimum & 1.37 & 0.51 & \\
\hline Maximum & 19.45 & 36.44 & \\
\hline LH/FSH & & & 0.025 \\
\hline $\mathrm{N}$ & 58 & 128 & \\
\hline Mean & 1.36 & 1.75 & \\
\hline Median & 1.09 & 1.26 & \\
\hline SD & 0.92 & 1.40 & \\
\hline Minimum & 0.26 & 0.13 & \\
\hline Maximum & 4.58 & 9.84 & \\
\hline
\end{tabular}

Total testosterone, free testosterone, androstenedione, DHEAS, LH, and estradiol levels and LH/FSH ratio were significantly higher in patients than in controls $(\mathrm{P}<0.05)$ (Table 2).

HOMA-IR was significantly higher in patients than in controls (44.9\% and 19\%, respectively; $\mathrm{P}=0.001$ ). When patients were divided into two group regarding their HOMA-IR status, patients with IR showed no significant differences with those without IR in BMI $(\mathrm{P}=0.117)$ and levels of total testosterone, androstenedione, and DHEAS $(\mathrm{P}=0.514, \mathrm{P}=0.602, \mathrm{P}=0.484$, and $\mathrm{P}=0.502$, respectively). No significant differences were observed in mean MPV value between patients and controls (mean, 9.02 fL (8.5-10.1) and 8.9 fL (7.7-9.1), respectively; $\mathrm{P}=$ 0.777). MPV values were also similar between controls and patients without IR $(\mathrm{P}>0.05)$. There was difference in MPV values between patients with high androgen levels (mean, 8.7 fL (7.1-11.9) and patients with normal levels (mean, 9.5 fL (6.9-13.2), $\mathrm{P}=0.012$ ) as well as between patients with high androgen levels and controls (mean, $8.9 \mathrm{fL}$ (7.7-9.1), P=0.04). No difference was observed between patients with normal androgen hormones levels and controls in MVP values ( $\mathrm{P}>0.05)$. There was a negative correlation between total testosterone and DHEAS with MPV $(\mathrm{P}=0.016, \mathrm{r}=-0.229 ;$ and $\mathrm{P}=0.006, \mathrm{r}=-0.261$, respectively) (Table 3 and Figures 1 and 2). Multiple logistic regression analyses confirmed the independence of these associations (Table 4 ).

Table 3. Assessment of the Correlation Between Androgen Hormones and Mean Platelet Volume in Patients With Polycystic Ovary Syndrome ${ }^{a}$

\section{Correlation Between Serum Concentration of An- drogen Hormones and Mean Platelet Volume}

\section{Free Testosterone}

r

Pvalue

$-0.164$

$\mathrm{N}$

0.102

\section{Total Testosterone}

r

Pvalue

$\mathrm{N}$

0.016

Androstenedione

\begin{tabular}{lc}
$\mathrm{r}$ & 0.040 \\
Pvalue & 0.732 \\
$\mathrm{~N}$ & 77 \\
DHEAS & \\
$\mathrm{r}$ & -0.261 \\
Pvalue & 0.006 \\
$\mathrm{~N}$ & 109 \\
\hline
\end{tabular}

${ }^{\mathrm{a}}$ Abbreviations: MPV, mean platelet volume; $\mathrm{r}$, correlation coefficient; $\mathrm{N}$, number of the patients with PCOS; and DHEAS, dehydroepiandrosterone-sulfate. 


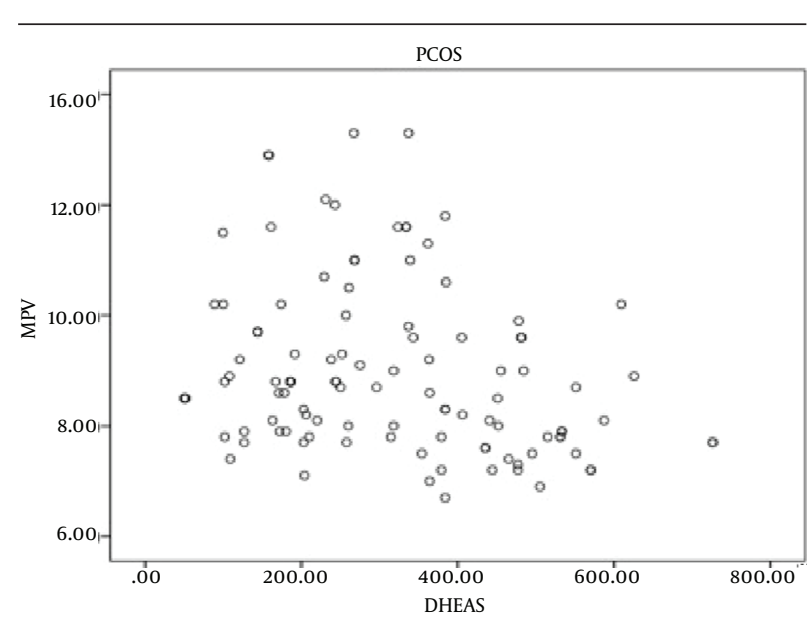

Figure 1. The Negative Correlation Between Total Testosterone and Mean Platelet Volume.

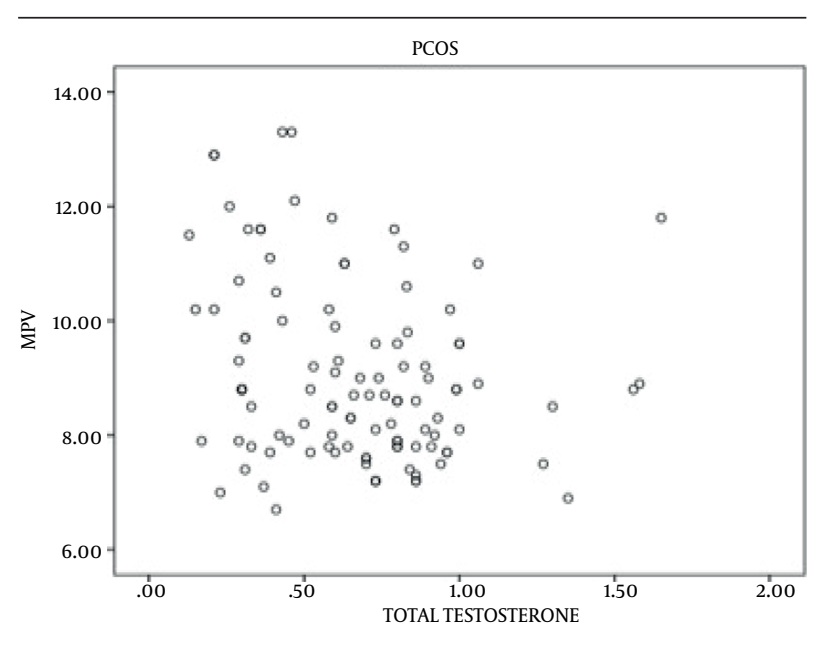

Figure 2. The Negative Correlation Between DehydroepiandrosteroneSulfate and Mean Platelet Volume.

Table 4. The Binary Logistic Regression Model Constructed to Investigate the Factors That Affect Mean Platelet Volume in Patients With Polycystic Ovary Syndrome

\begin{tabular}{|c|c|c|c|}
\hline & \multicolumn{2}{|c|}{ Coefficient of Regression } & \multirow[t]{2}{*}{ Pvalue } \\
\hline & Odds Ratio & Std. Error & \\
\hline DHEAS ${ }^{a}$ & 15.102 & 1.609 & $<0.001$ \\
\hline Total Testosterone & -1.214 & 0.436 & 0.007 \\
\hline
\end{tabular}

a Abbreviations: DHEAS, dehydroepiandrosterone-sulfate.

\section{Discussion}

PCOS leads to developing inflammation and atherosclerosis. Many recent studies have demonstrated the close relationship between atherosclerosis and increased MPV (8-12). Our study revealed that MPV did not differ between nonobese women with PCOS and controls. In contrast, a previous study reported an increased MPV in women with PCOS in comparison to non-PCOS controls (20). The discrepancy between the findings of two studies could be due the inclusion of obese patients with PCOS in the previous study and increased MPV in this population might occur as a consequence of obesity, which is known to causes increased MPV (15). A recent study including nonobese and obese patients with PCOS demonstrated that MPV did not correlate with PCOS except in patients with obesity (23). According to $\operatorname{AES}(4,5)$ and a review $(24,25)$, growing evidence links androgens with pathophysiology of PCOS and metabolic derangements. Moreover, a recent study has announced that hyperandrogenism might be the progenitor of inflammation, which is independent of obesity in the patients with PCOS. The authors declared that further studies are needed to evaluate the effect of androgen hormones on metabolic abnormalities in patients with PCOS (26). In this regard, a recent study has reported a positive correlation between MPV and DHEAS levels in PCOS (20). In contrast, our study showed that high levels of androgens were associated with the low MPV values in the nonobese patients with PCOS. This contrast might be due to enrolling obese patients and a smaller sample size of the former study. Thus, we suggest that the studies that aim to investigate the association between MPV and any hormonal/metabolic parameters in patients with PCOS must exclude the patients with risk factors of atherosclerotic such as obesity, which may affect MPV. In addition, recent studies support an increased incidence of cardiovascular events related to IR and/or obesity in patients with PCOS (27). In our study, IR was higher in nonobese women with PCOS than in healthy controls. Our study showed no differences in MPV values among patients with and without IR. Additionally, we did not detect any association between IR and MPV. All these findings suggest that IR might not be an independent risk factor for MPV changes in nonobese patients with PCOS.

Finally, if the result of our study could be confirmed by prospective studies including four groups, namely, obese women with PCOS, nonobese women with PCOS, nonobese healthy women, and obese healthy women, the effect of obesity on MPV could be better understood. Our study showed that MPV values did not change in nonobese women with PCOS. Additionally, IR, which is one of the most common features of PCOS, was not related to MPV in nonobese patients with PCOS. Lastly, we showed that elevated androgen levels caused a decrease in MPV in the same population.

\section{Author's Contributions}

BAD led the conception and design, review of literature, and drafted the manuscript. AA and MMT participated in design and coordination of the study. EK, ID and YT gave the concept of the research paper. DB and SG reviewed the manuscript.

\section{Financial Disclosure}

The authors declare that there are no conflicts of interest relevant to the materials presented herein and that 
the study protocol complied with current Turkish laws.

\section{References}

1. Carmina E, Lobo RA. Polycystic ovary syndrome(PCOS): arguably the most common endocrinopathy is associated with significant morbidity in women. J Clin Endocrinol Metab. 1999;84(6):1897-9.

2. Azziz R, Woods KS, Reyna R, Key TJ, Knochenhauer ES, Yildiz BO. The prevalence and features of the polycystic ovary syndrome in an unselected population. J Clin Endocrinol Metab. 2004;89(6):2745-9.

3. Rotterdam EA-SPCWG. Revised 2003 consensus on diagnostic criteria and long-term health risks related to polycystic ovary syndrome. Fertil Steril. 2004;81(1):19-25.

4. Shroff R, Syrop CH, Davis W, Van Voorhis BJ, Dokras A. Risk of metabolic complications in the new PCOS phenotypes based on the Rotterdam criteria. Fertil Steril. 2007;88(5):1389-95.

5. Azziz R, Carmina E, Dewailly D, Diamanti-Kandarakis E, EscobarMorreale HF, Futterweit W, et al. The Androgen Excess and PCOS Society criteria for the polycystic ovary syndrome: the complete task force report. Fertil Steril. 2009;91(2):456-88.

6. Teng HW, Chien YW, Hsu MI, Chen CI. The relationship between carotid intima-media thickness and endogenous androgens in young women with polycystic ovary syndrome in Taiwan. Gynecol Endocrinol. 2013;29(3):238-41.

7. Koiou E, Tziomalos K, Katsikis I, Kalaitzakis E, Kandaraki EA, Tsourdi EA, et al. Circulating platelet-derived microparticles are elevated in women with polycystic ovary syndrome diagnosed with the 1990 criteria and correlate with serum testosterone levels. Eur J Endocrinol. 2011;165(1):63-8.

8. Christakou CD, Diamanti-Kandarakis E. Role of androgen excess on metabolic aberrations and cardiovascular risk in women with polycystic ovary syndrome. Womens Health (Lond Engl). 2008;4(6):583-94.

9. Book CB, Dunaif A. Selective insulin resistance in the polycystic ovary syndrome. J Clin Endocrinol Metab.1999;84(9):3110-6.

10. Kelly CC, Lyall H, Petrie JR, Gould GW, Connell JM, Sattar N. Low grade chronic inflammation in women with polycystic ovarian syndrome. J Clin Endocrinol Metab. 2001;86(6):2453-5.

11. Paradisi G, Steinberg HO, Hempfling A, Cronin J, Hook G, Shepard MK, et al. Polycystic ovary syndrome is associated with endothelial dysfunction. Circulation. 2001;103(10):1410-5.

12. Orio F, Jr, Palomba S, Cascella T, De Simone B, Di Biase S, Russo T, et al. Early impairment of endothelial structure and function in young normal-weight women with polycystic ovary syndrome. $J$ Clin Endocrinol Metab. 2004;89(9):4588-93.

13. Gonzalez F, Rote NS, Minium J, Kirwan JP. Evidence of proathero- genic inflammation in polycystic ovary syndrome. Metabolism. 2009;58(7):954-62.

14. Vizioli L, Muscari S, Muscari A. The relationship of mean platelet volume with the risk and prognosis of cardiovascular diseases. Int J Clin Pract. 2009;63(10):1509-15.

15. Coban E, Ozdogan M, Yazicioglu G, Akcit F. The mean platelet volume in patients with obesity. Int J Clin Pract. 2005;59(8):981-2.

16. Kodiatte TA, Manikyam UK, Rao SB, Jagadish TM, Reddy M, Lingaiah HKM, et al. Mean platelet volume in Type 2 diabetes mellitus. J Lab Physicians. 2012;4(1):5.

17. Tavil Y, Sen N, Yazici HU, Hizal F, Abaci A, Cengel A. Mean platelet volume in patients with metabolic syndrome and its relationship with coronary artery disease. Thromb Res. 2007;120(2):24550.

18. Nechita A, Delcea C, Enache V, Ploesteanu RL, Cazacu C, Andronescu AM, et al. Metabolic syndrome and mean platelet volume variation in patients with chest pain and negative cardiac enzymes. J Med Life. 2013;6(2):156-60.

19. Bath P, Algert C, Chapman N, Neal B, Progress Collaborative Group . Association of mean platelet volume with risk of stroke among 3134 individuals with history of cerebrovascular disease. Stroke. 2004;35(3):622-6.

20. Kebapcilar L, Taner CE, Kebapcilar AG, Sari I. High mean platelet volume, low-grade systemic coagulation and fibrinolytic activation are associated with androgen and insulin levels in polycystic ovary syndrome. Arch Gynecol Obstet. 2009;280(2):187-93.

21. Hatch R, Rosenfield RL, Kim MH, Tredway D. Hirsutism: implications, etiology, and management. Am J Obstet Gynecol. 1981;140(7):815-30.

22. Rosenfield RL. Clinical review: Identifying children at risk for polycystic ovary syndrome. J Clin Endocrinol Metab. 2007;92(3):787-96.

23. Silfeler DB, Kurt RK, Yengil E, Un B, Arica S, Baloglu A. Evaluation of Mean Platelet Volume values in lean women with polycystic ovary syndrome. PakJ Med Sci. 2014;30(3):589-92.

24. Nisenblat V, Norman RJ. Androgens and polycystic ovary syndrome. Curr Opin Endocrinol Diabetes Obes. 2009;16(3):224-31.

25. Alemzadeh R, Kichler J, Calhoun M. Spectrum of metabolic dysfunction in relationship with hyperandrogenemia in obese adolescent girls with polycystic ovary syndrome. EurJEndocrinol. 2010;162(6):1093-9.

26. Gonzalez F, Sia CL, Bearson DM, Blair HE. Hyperandrogenism induces a proinflammatory TNFalpha response to glucose ingestion in a receptor-dependent fashion. J Clin Endocrinol Metab. 2014;99(5):E848-54.

27. Castelo-Branco C, Steinvarcel F, Osorio A, Ros C, Balasch J. Atherogenic metabolic profile in PCOS patients: role of obesity and hyperandrogenism. Gynecol Endocrinol. 2010;26(10):736-42. 